\title{
(2) OPEN ACCESS \\ Does NICE apply the rule of rescue in its approach to highly specialised technologies?
}

\author{
Victoria Charlton
}

Global Health and Social Medicine, School of Social Science and Public Policy, King's College London, London, UK

\section{Correspondence to} Victoria Charlton, Global Health and Social Medicine, King's College London School of Social Science and Public Policy, London WC2B 4BG, UK; victoria.charlton@kcl.ac.uk

Received 1 August 2020 Revised 21 December 2020 Accepted 6 January 2021
Check for updates

(c) Author(s) (or their employer(s)) 2021. Re-use permitted under CC BY. Published by BMJ.

\section{To cite: Charlton V.}

$J$ Med Ethics Epub ahead of print: [please include Day Month Year]. doi:10.1136/ medethics-2020-106759

\section{ABSTRACT}

The National Institute for Health and Care Excellence (NICE), the UK's main healthcare priority-setting body, recently reaffirmed a longstanding claim that in recommending technologies to the National Health Service it cannot apply the 'rule of rescue'. This paper explores this claim by identifying key characteristics of the rule and establishing to what extent these are also features of NICE's approach to evaluating ultra-orphan drugs through its highly specialised technologies (HST) programme. It argues that although NICE in all likelihood does not act because of the rule in prioritising these drugs, its actions in relation to HSTs are nevertheless in accordance with the rule and are not explained by the full articulation of any alternative set of rationales. That is, though NICE implies that its approach to HSTs is not motivated by the rule of rescue, it is not explicit about what else might justify this approach given NICE's general concern with overall population need and value for money. As such, given NICE's reliance on notions of procedural justice and its commitment to making the reasons for its priority-setting decisions public, the paper concludes that NICE's claim to reject the rule is unhelpful and that NICE does not currently meet its own definition of a fair and transparent decision-maker.

\section{INTRODUCTION}

The National Institute for Health and Care Excellence (NICE) is the UK's main healthcare priority-setting body, responsible for making recommendations about what technologies users of the National Health Service (NHS) in England should have access to. NICE's recommendations are made, prima facie, on the basis of a technology's cost-effectiveness: the number of additional quality-adjusted life-years (QALYs) it provides per unit of additional cost, compared with current NHS treatment (its incremental cost-effectiveness ratio or ICER). However, 'other factors' are sometimes invoked in order to prioritise the needs of particular groups, even if this results in the NHS delivering fewer QALYs overall. ${ }^{12}$ One group of technologies that is systematically prioritised in this way is ultra-orphan drugs for very rare diseases $\mathrm{s}^{\mathrm{i}}$, appraised through NICE's highly specialised technologies (HST) programme. ${ }^{3}$

Although NICE is open about the role that factors aside from cost-effectiveness play in its approach, it maintains that 'the primary consideration

${ }^{\mathrm{i}}$ Orphan drugs are usually defined as drugs in which the prevalence of the condition for which they are indicated does not exceed 5 in 10000 patients (ie, 1 in 2000). Ultra-orphan drugs are typically defined as drugs for which prevalence does not exceed 1 in 50000 patients. ${ }^{44}$ underpinning our guidance and standards is the overall population need'. ${ }^{2}$ It also states that it 'cannot apply the 'rule of rescue', which refers to the desire to help an identifiable person whose life is in danger no matter how much it costs'. ${ }^{2}$ This paper explores the latter claim by identifying key characteristics of the rule and establishing to what extent these are also features of NICE's approach to appraising HSTs. It argues that although NICE in all likelihood does not act because of the rule of rescue in prioritising HSTs, these actions are nevertheless in accordance with the rule and are not explained by the full articulation of any alternative set of rationales. The implications of this finding for the transparency and fairness of NICE decision-making are briefly discussed.

\section{THE RULE OF RESCUE}

The term 'rule of rescue' ${ }^{\text {,ii }}$ was coined by the medical ethicist Jonsen in 1986 to describe the moral challenge that life-saving technologies pose to the utilitarian ethics of health technology assessment (HTA). In Jonsen's words:

\begin{abstract}
'Our moral response to the imminence of death demands that we rescue the doomed. We throw a rope to the drowning, rush into burning buildings to snatch the entrapped, dispatch teams to search for the snowbound. This rescue morality spills over into medical care, where our ropes are our artificial hearts, our rush is the mobile critical care units, our teams the transplant services. The imperative to rescue is, undoubtedly, of great moral significance: but the imperative seems to grow into a compulsion, more instinctive than rational. ${ }^{4}$
\end{abstract}

Jonsen described the rule as a 'deontological imperative' and, though aware of its problematic implications, he considered it to play an inevitable role in healthcare priority setting, inferring that 'even the most evangelical utilitarian would find it difficult to expunge the rule of rescue from the psychological dynamics' of HTA. ${ }^{4}$ This was confirmed during the infamous Oregon prioritysetting exercise, in which a ranking of healthcare services based on cost-effectiveness alone had to be substantially re-ordered to account for both policy-makers' and the public's desire to prioritise

${ }^{\text {ii }} \mathrm{A}$ distinction is drawn in this paper between the 'rule of rescue' and the 'duty of easy rescue', which limits the moral relevance of any duty to rescue to cases in which a person can prevent serious harm to another at minimal cost to themselves. ${ }^{11}$ Given that NICE specifically describes its position in relation to the former rather than the latter, this paper does the same. 
- The powerful human proclivity to rescue endangered life.[6]

- The rule of rescue tells us to help identifiable individuals who are at risk of harm.[7]

- The powerful human proclivity to rescue a single identified endangered life, regardless of cost, at the expense of many nameless faces who will therefore be denied health care.[8]

- The rule of rescue describes the moral impulse to save identifiable lives in immediate danger at any expense.[9]

- We ought to attempt to rescue an individual when we are reasonably confident that our efforts can help, and when the individual's death is imminent and our failure to act is reasonably expected to result in that person's death.[10]

- The rule of rescue has two main components: it prioritises saving one or few lives at the opportunity cost of providing a large number of other people with smaller benefits, and it prioritises identifiable over unidentified lives.[11]

- The imperative to rescue identifiable individuals facing avoidable death, without giving too much thought to the opportunity cost of doing so.[12]

- Very roughly, the Rule of Rescue involves society spending large amounts of resources 'rescuing' identifiable individuals who are in imminent danger.[13]

- According to this principle more funding should be available in order to save lives of identifiable, compared with unidentifiable, individuals.[14]

- The injunction to rescue identifiable individuals in immediate peril, regardless of cost.[15]

- A moral rule prescribing the rescue of identifiable people at immediate risk of serious harm.[16]

Figure 1 Selected definitions of the rule of rescue. ${ }^{6-16}$

potentially life-saving treatments (such as appendectomies) over more efficient interventions (such as tooth capping). ${ }^{5-7}$

The rule of rescue has since been interpreted in various ways, ranging from highly demanding definitions that narrowly limit its application ${ }^{8-11}$ to less restrictive characterisations that allow for wider adoption (figure 1). ${ }^{6} 12-15$ Definitions are generally consistent, however, in including three criteria that together might be considered to reflect the substance of Jonsen's rule, which are:

I. The intervention must offer significant benefits to those at risk of death or other serious harm.

II. The beneficiaries of the rescue must be identifiable.

III. The rescuer must be willing to bear significant opportunity cost in order to carry out the rescue. iii

While some definitions describe the rule of rescue as being psychologically motivated, ${ }^{6}$ others give it the status of a normative principle. ${ }^{101416}$ It is beyond this paper's scope to consider whether the rule can be morally justified, but it is notable that much of the literature is sceptical on this point. ${ }^{9-11}{ }^{14-18}$ The principle of prioritising those in greatest need, even when this leads to significant opportunity cost, is supported by strong moral arguments ${ }^{19}$ and is commonly adopted in HTA. ${ }^{20-22}$ However, the rule's additional reliance on identifiability appears problematic. Indeed, 'attempts at providing a morally significant definition of identifiability have met formidable criticism from philosophers', with identifiability 'simply collaps(ing) into salience of the victim's need', which 'does not constitute any moral reason for favouring some people over others'. ${ }^{11}$ Thus, while there is clearly a psychological difference between 'Terry Q., lying injured in the passenger seat of the wrecked automobile on the corner of main street and broadway', and 'the person who, extrapolating from traffic records, will be in a similar, serious car accident tomorrow, ${ }^{23}$ it is not clear that this often observed preference-the so-called identifiable victim effect ${ }^{24}$ - can be morally justified.

NICE itself refers to the rule of rescue as a 'desire' and its interpretation of the rule is unusually narrow in being limited to scenarios in which a single identifiable person whose life is at

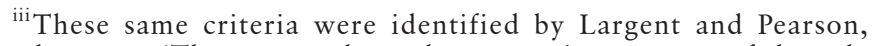
who state: 'There are at least three constituent parts of the rule of rescue-identifiable individuals, endangered lives and opportunity costs'.
}

risk is helped, with no regard given to cost. ${ }^{2}$ Given that NICE is statutorily required to 'have regard to the broad balance between the benefits and costs' of the technologies that it considers ${ }^{25}$ and given that its recommendations necessarily relate to populations rather than individuals, it is inevitable that NICE will not be found to adopt the rule as thus defined. However, the rule is generally understood more broadly and was coined by Jonsen to describe precisely the types of dilemma that NICE regularly confronts, perhaps most vividly in its consideration of HSTs. This paper therefore does not take NICE's claim to reject the rule at face value, but rather explores the extent to which the HST programme might be considered to adopt the rule as it is commonly understood.

\section{NICE'S APPRAISAL OF HSTS}

NICE's HST programme, specifically for the appraisal of ultraorphan drugs, was established in 2013. Previously the responsibility of the Advisory Group for National Specialised Services (AGNSS), evaluation of these technologies had historically taken account of a range of factors aside from cost-effectiveness, in recognition of the difficulties associated with developing treatments for very small patient populations. ${ }^{26}$ In taking over AGNSS's role, NICE agreed that an approach 'in which the greatest gain for the greatest number is valued highly' would not reflect 'the particular circumstances of these very rare conditions' ${ }^{327}$ As such, it judged that while orphan drugs considered via the main technology appraisal programme should continue to be evaluated 'in the same way as any other treatment', ${ }^{28}$ ultraorphan drugs considered via the HST programme would be evaluated according to different criteria. ${ }^{327}$

The most significant difference relates to the ICER at which a technology is deemed to be an acceptable use of NHS resources. In the main programme, the generally applied cost-effectiveness 'threshold' is $£ 20$ 000- $£ 30000 / Q A L Y$, increasing to $£ 50000 /$ QALY for technologies that are life-extending at the end of life. ${ }^{1}$ In the HST programme, the equivalent figure is $£ 100000$ / QALY, increasing to $£ 300000$ /QALY for technologies that offer particularly large health gains. ${ }^{3}$ Given the advantage this offers to those who stand to benefit from a technology's recommendation, appraisal via the programme is desirable for manufacturers and patient groups. However, restrictive eligibility criteria mean that only 13 drugs have been appraised as HSTs to date 
HSTs are selected using the following criteria, [2] all of which have to apply:

- The target patient group for the technology in its licensed indication is so small that treatment will usually be concentrated in very few centres in the NHS;

- The target patient group is distinct for clinical reasons;

- The condition is chronic and severely disabling;

- The technology is expected to be used exclusively in the context of a highly specialised service;

- The technology is likely to have a very high acquisition cost;

- The technology has the potential for life long use;

- The need for national commissioning of the technology is significant.

Figure 2 HST eligibility criteria. ${ }^{2}$ HST, highly specialised technology; NHS, National Health Service.

(figure 2). In each case, NICE recommended that the drug be adopted by the NHS.

\section{THE HST PROGRAMME AND THE RULE OF RESCUE}

This section examines whether the HST programme might be considered to apply the rule of rescue by exploring the extent to which it fulfils the three criteria that are together taken to constitute the substance of the rule.

\section{Criterion 1: the intervention must offer significant benefits to those at risk of death or other serious harm}

In the context of HTA, a 'rescue' involves providing someone who suffers from a serious medical condition with access to a potentially beneficial treatment. Understood as such, almost any effective treatment for a severe condition might be considered a form of rescue. However, most definitions of the rule demand more: the condition should be either life-threatening or severely debilitating and the intervention should be capable of either saving the endangered life or offering very considerable benefit.

Eligibility for appraisal via the HST programme is limited to conditions that are, at a minimum, 'severely disabling'. ${ }^{3}$ Although this does not require that patients be at imminent risk of death, in 10 of the 13 completed HST appraisals the treated condition is associated with significantly reduced life expectancy (table 1). In each case, the treatment has been shown to potentially offer large benefits, in terms of either length of life, quality of life or both; of the 13 appraised drugs, 10 were considered likely to offer five or more additional QALYs over the course of a patient's lifetime compared with existing treatment, and in eight cases the feasible range reached 12 QALYs or more. In comparison, research has indicated that new medicines subject to HTA typically offer a mean lifetime gain of around 0.5 QALYs. ${ }^{\text {iv }} 29$

This potential for large health gains is in part a product of the HST programme's focus on severely disabling conditions, since patients suffering from these conditions are likely to be in a poor state of health, providing a low QALY baseline against which the benefits of treatment will be compared. In addition, the high cost of many ultra-orphan drugs makes it unlikely that such products would be brought to market unless there was a reasonable prospect of their prices being justified by significant clinical benefits. Thus, the design and scope of the HST programme make it extremely likely that the technologies it evaluates will offer significant benefits to those at risk of death or other serious harm-an expectation that has so far been borne out in practice.

\footnotetext{
${ }^{\text {iv }}$ Based on new medicines appraised through the Scottish Medicine Consortium-which has a similar scope to the NICE core appraisal programme-between 2001 and 2010.
}

\section{Criterion 2: the beneficiaries of the rescue must be identifiable}

As a national priority setter, NICE's advice invariably relates to patient populations rather than individuals. However, the beneficiaries of its recommendations are arguably always identifiable because their eligibility for treatment with a given technology distinguishes them from other NHS users. In contrast, those NHS users who bear the opportunity cost of NICE's recommendations are entirely unidentifiable, because NICE has no knowledge of what will be displaced in order to fund its recommendations. As such, it could be argued that all NICE appraisals meet this criterion, regardless of the size of the affected population.

Alternatively, it could be argued that NICE's appraisals never meet this criterion, because its recommendations apply to both identifiable current patients and unidentifiable future patients who have not yet been diagnosed (or perhaps even born). However, the purpose here is not to suggest that NICE's appraisals meet all possible standards of identifiability, but is only that they meet the relatively weak standard implied by the rule of rescue. In making this argument, a comparison can be drawn with Jonsen's formative example of the artificial heart, which 'might annually bring 4 years of extended life to some 25000 persons' with cardiomyopathy at the expense of the 'invisible multitudes' who die of other conditions, and a typical NICE recommendation, which benefits a few thousand patients while exacting an opportunity cost on millions of unknown NHS users. ${ }^{4}$ Considered in this light, even though NICE's recommendations apply to both current and future patients, it is difficult to argue that they fail to meet the standard of identifiability intended by Jonsen when he coined the rule of rescue.

The potential beneficiaries of ultra-orphan drugs are also identifiable in a stronger sense much closer to that of 'Terry Q.', lying injured at the side of the road, in need of rescue. ${ }^{23}$ Across the 13 HST appraisals completed to date, the most common condition affected an estimated 250 UK patients at the time of appraisal, with several recommendations applying to fewer than 10 new patients annually (table 1). In one case, it was anticipated that the treatment would be given to a single patient each year. ${ }^{v}$ Such small group sizes, combined with the distinctive and serious nature of the related conditions, make these patients highly identifiable and their needs especially salient. This salience is further enhanced by NICE's practice of inviting patients and carers to describe their experiences through oral

\footnotetext{
${ }^{\text {v} A s ~ p a r t ~ o f ~ N I C E ' s ~ 2017 / 18 ~ a p p r a i s a l ~ o f ~ S t r i m v e l i s ~ f o r ~ t r e a t i n g ~}$ adenosine deaminase deficiency-severe combined immunodeficiency (ADA-SCID, also known as 'bubble baby' disease because of the extreme vulnerability of its sufferers to infection), the company estimated that 'three people a year would be diagnosed with ADA-SCID in England'. Of these, it was expected that one person would be treated with Strimvelis at a cost of approximately $£ 500000$.
} 


\begin{tabular}{|c|c|c|c|c|c|c|}
\hline Reference & $\begin{array}{l}\text { Technology (brand)/ } \\
\text { indication }\end{array}$ & Prognosis without treatment & $\begin{array}{l}\text { Patient population } \\
\text { size (England) }\end{array}$ & QALY gain & ICER* ( $\left.^{*} / \mathrm{QALY}\right)$ & Recommendation†¥ \\
\hline HST $1^{45-47}$ & $\begin{array}{l}\text { Eculizumab (Soliris)/atypical } \\
\text { haemolytic uraemic syndrome }\end{array}$ & $\begin{array}{l}\text { Acute mortality ranges from } 10 \% \text { to } \\
15 \% \text {; up to } 70 \% \text { of patients progress to } \\
\text { end-stage renal failure and need dialysis } \\
\text { or die within the first year of disease. }\end{array}$ & $\begin{array}{l}\text { Estimated } 170 \text { eligible } \\
\text { patients at the time of } \\
\text { appraisal; } 20 \text { patients } \\
\text { per year thereafter. }\end{array}$ & $10-25$ & $\begin{array}{l}\text { Not applicable } \\
\text { (n/a) }\end{array}$ & $\begin{array}{l}\text { Unable to prepare } \\
\text { a recommendation; } \\
\text { recommended; } \\
\text { recommended }\end{array}$ \\
\hline HST $2^{48-50}$ & $\begin{array}{l}\text { Elosulfase alfa (Vimizim)/ } \\
\text { mucopolysaccharidosis type } \\
\text { IVa }\end{array}$ & $\begin{array}{l}\text { Variable. Severe disease is early onset } \\
\text { ( }<3 \text { years), with high morbidity and } \\
\text { rapid progression. The condition leads } \\
\text { to reduced life expectancy, primarily } \\
\text { through respiratory failure and heart } \\
\text { problems. }\end{array}$ & $\begin{array}{l}\text { Estimated } 74-77 \\
\text { eligible patients at } \\
\text { the time of appraisal; } \\
\text { three patients per year } \\
\text { thereafter. }\end{array}$ & $5-20$ & $\mathrm{n} / \mathrm{a}$ & $\begin{array}{l}\text { Minded not to recommend; } \\
\text { recommended; } \\
\text { recommended (MAS) }\end{array}$ \\
\hline HST $3^{5152}$ & $\begin{array}{l}\text { Ataluren (Translarna)/ } \\
\text { Duchenne muscular dystrophy } \\
\text { (DMD) with a non-sense } \\
\text { mutation in the dystrophin } \\
\text { gene }\end{array}$ & $\begin{array}{l}\text { People with DMD have a gradual decline } \\
\text { in physical functioning, with subsequent } \\
\text { respiratory and cardiac failure that leads } \\
\text { to death, usually before age } 30 \text { years. }\end{array}$ & $\begin{array}{l}\text { Estimated } 80 \text { eligible } \\
\text { patients at the time of } \\
\text { appraisal. }\end{array}$ & $2.9-8.6$ & $\mathrm{n} / \mathrm{a}$ & $\begin{array}{l}\text { Minded not to recommend; } \\
\text { recommended (MAS, } \\
\text { PAS) }\end{array}$ \\
\hline HST $4^{5354}$ & $\begin{array}{l}\text { Migalastat (Galafold)/Fabry } \\
\text { disease }\end{array}$ & $\begin{array}{l}\text { Variable. The disease leads to irreversible } \\
\text { organ damage, resulting in progressive } \\
\text { kidney and heart disease and increased } \\
\text { risk of stroke at a relatively young age. } \\
\text { Fabry disease is associated with both } \\
\text { reduced quality of life and reduced life } \\
\text { expectancy. }\end{array}$ & $\begin{array}{l}\text { Estimated } 142 \text { eligible } \\
\text { patients at the time of } \\
\text { appraisal. }\end{array}$ & $0.3-1.0$ & $\mathrm{n} / \mathrm{a}$ & $\begin{array}{l}\text { Recommended; } \\
\text { recommended (PAS) }\end{array}$ \\
\hline HST $5^{5556}$ & $\begin{array}{l}\text { Eliglustat (Cerdelga)/type } 1 \\
\text { Gaucher disease }\end{array}$ & $\begin{array}{l}\text { Variable. Gaucher disease causes } \\
\text { symptoms such as fatigue, bone pain } \\
\text { and reduced mobility. People who } \\
\text { present early have a particularly poor } \\
\text { prognosis and usually develop bone } \\
\text { disease and immobility in the third or } \\
\text { fourth decade of life, with a high early } \\
\text { mortality. }\end{array}$ & $\begin{array}{l}\text { Approximately } 50-100 \\
\text { eligible patients at the } \\
\text { time of appraisal. }\end{array}$ & $1.0-1.1$ & $\mathrm{n} / \mathrm{a}$ & $\begin{array}{l}\text { Not recommended; } \\
\text { recommended (PAS) }\end{array}$ \\
\hline HST $6^{57-59}$ & $\begin{array}{l}\text { Asfotase alfa (Strensiq)/ } \\
\text { paediatric-onset } \\
\text { hypophosphatasia }\end{array}$ & $\begin{array}{l}\text { Symptoms are variable but include } \\
\text { chronic debilitating pain, rickets, } \\
\text { softening and weakening of the bones, } \\
\text { bone deformity and a greater incidence } \\
\text { of fractures. The most severe forms tend } \\
\text { to occur before birth and in early infancy. } \\
\text { About } 50 \%-100 \% \text { of babies presenting } \\
\text { with the condition die within the first } \\
\text { year of life. }\end{array}$ & $\begin{array}{l}\text { Between } 1 \text { and } 7 \\
\text { eligible patients per } \\
\text { year. }\end{array}$ & $14-25$ & $\mathrm{n} / \mathrm{a}$ & $\begin{array}{l}\text { Not recommended; } \\
\text { recommended (perinatal- } \\
\text { onset and infantile-onset } \\
\text { only); recommended (all } \\
\text { paediatric onset, PAS, } \\
\text { MAS) }\end{array}$ \\
\hline HST $7^{6061}$ & $\begin{array}{l}\text { Strimvelis/adenosine } \\
\text { deaminase deficiency-severe } \\
\text { combined immunodeficiency }\end{array}$ & $\begin{array}{l}\text { The main feature of ADA-SCID is a } \\
\text { severely compromised immune system, } \\
\text { which, if untreated, requires the patient } \\
\text { to be isolated, severely impacting quality } \\
\text { of life. Untreated infants typically die } \\
\text { before school age. }\end{array}$ & $\begin{array}{l}\text { The company estimated } \\
\text { that three people a } \\
\text { year are diagnosed } \\
\text { with ADA-SCID and } \\
\text { that one person a year } \\
\text { would have Strimvelis } \\
\text { treatment. }\end{array}$ & $14.0-19.6$ & $<120506$ & $\begin{array}{l}\text { Recommended; } \\
\text { recommended }\end{array}$ \\
\hline HST $8^{6263}$ & $\begin{array}{l}\text { Burosumab (Crysvita)/X- } \\
\text { linked hypophosphataemia in } \\
\text { children and young people }\end{array}$ & $\begin{array}{l}\text { Early signs include skeletal abnormalities } \\
\text { such as bowed or bent legs, below } \\
\text { average height and irregular growth } \\
\text { of the skull. Bone defects are common } \\
\text { in children and can cause pain and } \\
\text { subsequently limit physical functioning. } \\
\text { When bone growth stops, bone } \\
\text { deformities become irreversible and can } \\
\text { be the source of continuing pain. }\end{array}$ & $\begin{array}{l}\text { Up to } 250 \text { eligible UK } \\
\text { patients at the time of } \\
\text { appraisal. }\end{array}$ & $5.5-16.0$ & $113000-150000$ & $\begin{array}{l}\text { Not recommended; } \\
\text { recommended (PAS) }\end{array}$ \\
\hline HST $9^{6465}$ & $\begin{array}{l}\text { Inotersen (Tegsedi)/hereditary } \\
\text { transthyretin amyloidosis } \\
\text { (hATTR) }\end{array}$ & $\begin{array}{l}\text { People may have a range of symptoms } \\
\text { affecting one or more body systems. } \\
\text { These can include the autonomic } \\
\text { nervous system, peripheral nerves, } \\
\text { heart, gastrointestinal system, eyes and } \\
\text { central nervous system. The effects and } \\
\text { complications of the condition can lead } \\
\text { to death within 3-15 years of symptoms } \\
\text { developing. }\end{array}$ & $\begin{array}{l}\text { Approximately } 150 \\
\text { eligible UK patients at } \\
\text { the time of appraisal. }\end{array}$ & $<10$ & 96697 & $\begin{array}{l}\text { Not recommended; } \\
\text { recommended (PAS) }\end{array}$ \\
\hline
\end{tabular}




\begin{tabular}{|c|c|c|c|c|c|c|}
\hline Reference & $\begin{array}{l}\text { Technology (brand)/ } \\
\text { indication }\end{array}$ & Prognosis without treatment & $\begin{array}{l}\text { Patient population } \\
\text { size (England) }\end{array}$ & QALY gain & ICER* (f/QALY) $^{*}$ & Recommendationt‡ \\
\hline HST $10^{6667}$ & Patisiran (Onpattro)/hATTR & As above. & As above. & $9.2-12.2$ & $80730-125256$ & $\begin{array}{l}\text { Not recommended; } \\
\text { recommended (PAS) }\end{array}$ \\
\hline HST $11^{68}$ & $\begin{array}{l}\text { Voretigene neparvovec } \\
\text { (Luxturna)/inherited retinal } \\
\text { dystrophies caused by RPE65 } \\
\text { gene mutations }\end{array}$ & $\begin{array}{l}\text { People with the condition have } \\
\text { progressive vision loss, beginning as } \\
\text { early as the first few months of life, } \\
\text { or during childhood, or adolescence. } \\
\text { Ultimately, the deterioration leads to } \\
\text { near-total blindness. }\end{array}$ & $\begin{array}{l}\text { Approximately } 86 \\
\text { eligible patients at the } \\
\text { time of appraisal. }\end{array}$ & $12.1-17.7$ & $\begin{array}{l}114956-155750 \\
\text { (pre discount)§ }\end{array}$ & Recommended (PAS) \\
\hline HST $12^{69-71}$ & $\begin{array}{l}\text { Cerliponase alfa (Brineura)/ } \\
\text { neuronal ceroid lipofuscinosis } \\
\text { type } 2\end{array}$ & $\begin{array}{l}\text { Symptoms include a decline in mental } \\
\text { and other capacities, epilepsy and sight } \\
\text { loss in late infancy, leading to death by } \\
\text { early adolescence. Symptoms appear } \\
\text { in the second year of life and can then } \\
\text { progress rapidly. Ultimately, the child } \\
\text { will become totally dependent on family } \\
\text { and carers for all their needs. }\end{array}$ & $\begin{array}{l}\text { Approximately } 30-50 \\
\text { eligible UK patients at } \\
\text { the time of appraisal; } \\
3-6 \text { patients per year } \\
\text { thereafter. }\end{array}$ & $>30$ & $\begin{array}{l}>300000 \text { (pre } \\
\text { discount)§ }\end{array}$ & $\begin{array}{l}\text { Not recommended; } \\
\text { not recommended; } \\
\text { recommended (MAS) }\end{array}$ \\
\hline HST $13^{7273}$ & $\begin{array}{l}\text { Volanesorsen (Waylivra)/ } \\
\text { familial chylomicronaemia } \\
\text { syndrome }\end{array}$ & $\begin{array}{l}\text { Symptoms include repeated episodes } \\
\text { of severe abdominal pain, recurrent } \\
\text { episodes of acute pancreatitis, liver } \\
\text { and spleen enlargement, and fatigue. } \\
\text { Acute pancreatitis is a life-threatening } \\
\text { condition for which intensive care may } \\
\text { be needed. }\end{array}$ & $\begin{array}{l}\text { Approximately } 80-100 \\
\text { eligible UK patients at } \\
\text { the time of appraisal. }\end{array}$ & $<10$ & 98103 & $\begin{array}{l}\text { Not recommended; } \\
\text { recommended (PAS) }\end{array}$ \\
\hline
\end{tabular}

*Calculation of a technology's incremental cost-effectiveness ratio (ICER) did not form part of the formal methods of the HST process at the time that HTS1-HST6 took place. tProvisional decisions in normal type, final decisions indicated by bold type.

‡A PAS is the standard way for pharmaceutical companies to make high-cost drugs affordable for the NHS when they are routinely commissioned. Each scheme is approved by the Department of Health. They can be a simple discount or more complex (eg, price cap). A managed access scheme consists of two components: (1) a data collection arrangement, which sets out data that will be collected to resolve clinical uncertainty during the 'managed access' period, and (2) a commercial agreement that determines how much the NHS will pay for the treatment during the managed access period. This could be a PAS.

§ICERs for these appraisals are commercial in confidence and the figures quoted do not reflect the price paid by the NHS after the agreed discount has been applied. ADA-SCID, adenosine deaminase deficiency-severe combined immunodeficiency; HST, highly specialised technology; MAS, managed access scheme; NHS, National Health Service; PAS, patient access scheme; QALY, quality-adjusted life-year.

and written testimony. While such engagement is not unique to HSTs, the exceptionally small patient populations involved in these appraisals mean that decision-makers have direct contact with a much larger proportion of those who stand to benefit, reducing group anonymity and further increasing the extent to which the beneficiaries might come to feel 'known'. Thus, while all NICE's appraisals could be considered to meet the standard of identifiability required by Jonsen, those whose needs are addressed via the HST programme are also identifiable in sense much more likely to elicit the identifiable victim effect. ${ }^{2430}$

\section{Criterion 3: the rescuer must be willing to bear significant opportunity cost in order to carry out the rescue}

According to NICE's current methods, HSTs will generally be recommended up to an ICER of $£ 100$ 000/QALY, increasing to $£ 300000 / \mathrm{QALY}$ if the expected health gain is sufficiently large. ${ }^{3}$ In comparison, NICE's standard cost-effectiveness threshold is $£ 20000-£ 30000 / \mathrm{QALY},{ }^{1}$ with empirical evidence suggesting that the actual cost to the NHS of producing a single QALY lies between $£ 5000$ and $£ 15000 .{ }^{31-33}$ As such, for every QALY gained at a cost of $£ 100000-£ 300000$, between 6 and 60 QALYs are likely displaced from the NHS as a whole. Thus, while it cannot be claimed that the HST programme pays no regard to cost-(to do so would contravene NICE's statutory obligations) -its methods allow NICE to commit the NHS to very significant opportunity costs in order to provide access to these drugs.

Decisions made by the programme to date confirm NICE's willingness to accept this magnitude of opportunity cost in practice as well as policy. Although exact ICERs are often commercial in confidence due to price discounts secured following negotiation, several drugs have been recommended at a cost of around $£ 100000 / \mathrm{QALY}$, and, in one recent case, the final ICER appears to have been in the region of $£ 300000 / \mathrm{QALY}$ (table 1 and figure 3). Indeed, despite evaluating some of the most expensive drugs ever to have been brought to market and despite in several cases provisionally judging them to offer insufficient value for money to warrant recommendation, NICE has never rejected an HST. Thus, while there may be a point at which NICE is willing to turn its back on the potential 'rescues' offered by such drugs, that point has evidently not yet been reached in practice.

\section{DISCUSSION}

The rule of rescue is an amorphous concept that can be defined and used in a variety of ways. In claiming to reject the rule, NICE adopts a particularly narrow interpretation that is, in practical terms, incompatible with its role as a national priority setter. However, this rejection is in tension with an approach to appraising HSTs that might reasonably be considered to reflect the substance of the rule, as it is commonly understood. As such, while NICE's claim that it 'cannot apply' the rule of rescue should not be considered wrong, it also cannot be considered entirely right. ${ }^{2}$

That is not to suggest that in its design and conduct of the HST programme, NICE has sought to adopt the rule of rescue. That is, in Kantian terms, it is not argued that in facilitating access to these technologies NICE acts for the sake of the rule. ${ }^{34}$ 
Neuronal ceroid lipofuscinosis type 2 (CLN2) - a form of Batten disease - is a rare genetic disease caused by deficiency of an enzyme involved in protein and lipid storage. It progresses rapidly and predictably from presentation in late infancy to death by early adolescence and is characterised clinically by a decline in mental and other capacities, epilepsy and sight loss. It is estimated that, in the UK, around 3 to 6 children are diagnosed with this form of Batten disease each year and currently around 30 to 50 children are living with the condition.[69]

Cerliponase alpha (Brineura) is an enzyme replacement therapy consisting of a recombinant form of the affected enzyme. It is administered into the cerebrospinal fluid by infusion via a surgically implanted device and must be administered by a trained healthcare professional every two weeks. A standard $300 \mathrm{mg}$ dose has a list price of $£ 20,107$, giving rise to an annual drug-only treatment cost of $£ 522,782$ per patient.[69]

In November 2019, after an appraisal process spanning more than two years, NICE recommended cerliponase alpha for use by the NHS.[69] Prior to this recommendation, the committee had issued a provisional - and then a final decision not to recommend the drug on the basis that "cerliponase alfa does not appear to provide value for money", despite offering each patient 30 or more additional QALYs over the course of their lifetime compared with current care. The cost-effectiveness threshold used for decision-making was $£ 300,000 / Q A L Y$, in recognition of these large QALY gains.[69-71]

The final decision to reject the drug was later reversed following an unsuccessful appeal, further negotiation with the manufacturer, Biomarin, and a successful attempt by the Batten Disease Family Association to request a judicial review of the decision. [74] A commercial access agreement was put in place that likely grants the NHS a discount on the full list price; however the details of this arrangement are confidential. In explaining its recommendation, the committee took into account that "CLN2 is a rare, devastating condition, with a debilitating and life-limiting effect on children with the condition, and [...] a substantial emotional and financial impact on their families".[69] It understood that "there was an unmet need for an effective treatment" and concluded that "when applying a QALY weight of 3.0, the committee noted that, while highly uncertain, it was plausible that the ICER was within the range normally considered an effective use of NHS resources for highly specialised technologies."[69] Thus, while the final ICER is confidential, it seems likely that it remained close to the $f 300,000 / Q A L Y$ threshold used for decision-making.

Figure 3 Cerliponase alpha for the treatment of Batten disease ${ }^{69-7174}$. ICER, incremental cost-effectiveness ratio; NHS, National Health Service; NICE, National Institute for Health and Care Excellence; QALY, quality-adjusted life-year.

Rather, it is suggested that these actions are in accordance with the rule, while perhaps being motivated by a more complex set of normative considerations. This is an important distinction because the moral basis for the rule of rescue itself appears, at best, questionable. ${ }^{9-11}{ }^{14-18}$ In contrast, it is perfectly possible that the reasons that lead NICE to act in accordance with the rule provide a morally sound basis for decision-making.

NICE, however, is not explicit about these reasons. In describing its approach to HSTs, NICE refers to the 'particular circumstances of these very rare conditions', specifically 'the vulnerability of very small patient groups with limited treatment options, the nature and extent of the evidence and the challenge for manufacturers in making a reasonable return on their research and development investment'. 27 The programme's focus on conditions that are 'chronic and severely disabling' suggests that weight is also given to the severity of clinical need. ${ }^{3}$ But while NICE draws attention to these considerations, it is not explicit about the role they play in its approach to HSTs. It is therefore left to us to speculate as to why NICE considers these technologies worthy of such significant prioritisation compared with the many other technologies that it appraises.

A clue is offered by the other circumstances in which NICE is willing to exceed its usual $£ 20$ 000- $£ 30$ 000/QALY costeffectiveness threshold. The so-called 'end-of-life rules', introduced in 2009, allow appraisal committees to 'give greater weight to QALYs achieved in the later stages of terminal diseases', effectively raising the threshold for some life-extending technologies to $£ 50$ 000/QALY. ${ }^{135}$ The needs of severely ill young patients with limited treatment options are prioritised through the lower discount rate applied in cases in which large health gains are 'sustained over a very long period (normally at least 30 years)', and appraisal committees are also encouraged to give special consideration to the 'innovative nature' of technologies that may not otherwise be deemed cost-effective. ${ }^{1}$ Each of these prioritisation mechanisms are potentially applicable to HSTs, when the relevant criteria are met. There is also precedent for facilitating access to drugs for which 'the uncertainty in the clinical and cost-effectiveness data is too great to recommend the drug for routine use', through the special arrangements in place for NICE's operation of the Cancer Drugs Fund. ${ }^{35}$ Indeed, drugs approved through the HST programme are often subject to similar managed access arrangements in which further data collection is a condition of the NHS's adoption of a technology (table 1). None of these mechanisms, however, grant technologies sufficient priority to facilitate their recommendation at the $>£ 100000 /$ QALY ICERs typical of the HST programme. NICE's exceptionalisation of HSTs must therefore be based-at least in part-on other reasons.

The obvious candidate is rarity. Various bodies, including the UK Medicines and Healthcare products Regulatory Agency, confer special treatment on orphan and ultra-orphan drugs 'to encourage the development of medicines in rare diseases'. ${ }^{36}$ NICE's concern with 'the challenge for companies in making a reasonable return' on their investment suggests that its prioritisation of HSTs might be motivated by a similar desire to drive drug development. ${ }^{3}$ However, NICE does not make it clear why it considers either the development or adoption of ultra-orphan drugs to be a particular priority. This is not to say that reasonable justifications for such a view do not exist. A proponent of a rightsbased sufficientarian approach, ${ }^{37}$ for example, might assert that all individuals in a society are entitled to a decent minimum level of health (or healthcare) and that rare disease patients falling below this level should therefore be provided with access to treatment, whatever the cost. But NICE does not adopt a rightsbased approach and does not otherwise take account of notions of sufficiency in its decision-making. Alternatively, a luck egalitarian $^{38}$ might point out the misfortune of requiring treatment with an extremely expensive ultra-orphan drug and argue that 
resources should allocated in order to eliminate the disadvantage derived from such 'brute luck'. However, this seems incompatible with NICE's broadly utilitarian approach, which though sympathetic to the desirability of reducing health inequalities, generally considers allocative efficiency to be of greater importance. A promising argument for specifically prioritising conditions that are both rare and severe is offered by the notion of aggregate relevant claims, which suggests that any level of opportunity cost might be considered acceptable in helping the very sick, as long as the health burdens of those who suffer the cost are sufficiently small in comparison. ${ }^{\text {vi }} 39$ However, NICE's approach is generally insensitive to (and, in fact, ignorant of) the nature of the health displaced by its recommendations. Indeed, none of these potential rationales are compatible with NICE's general approach or able to explain why, under this approach, ultra-orphan drugs are granted substantial priority, while orphan drugs are granted none.

In the absence of a clear normative reason for NICE's exceptionalisation of HSTs, consideration must be given to other possible explanations. The cases considered through the HST programme tend to be highly emotive and distressing, often featuring young, vulnerable patients who suffer the double misfortune of having a life-limiting illness that is both very severe and very rare. In inheriting responsibility for the evaluation of ultra-orphan drugs from AGNSS, NICE was faced with the choice of either continuing to prioritise these technologies or publicly justifying why it does not consider them to offer sufficient value for money. It is easy to understand why it might have been considered politically expedient to choose the former option, even if this did not easily accord with NICE's wider approach. An argument could also be made that, while NICE decision-makers do not prioritise HSTs because of the rule of rescue and do not accept the rule as a normative principle, both are driven by the same psychological desire to 'rescue the doomed'. ${ }^{4}$ That is, in enacting a policy that-in an affordably small number of cases-substantially prioritises the needs of a highly identifiable and unfortunate few over the less salient many, NICE has itself succumbed to the identifiable victim effect.

Whatever its reasons for acting as it does, the disparity between NICE's explicit rejection of the rule of rescue and its apparent accordance with the rule in its treatment of HSTs potentially undermines the fairness of NICE's approach. This has historically been based largely on the notion of procedural justice and NICE's commitment to observing the terms of Daniels and Sabin's accountability for reasonableness framework, which requiresamong other things- that both priority-setting decisions and their rationales be made public. ${ }^{28}{ }^{40}$ However, as has been illustrated, NICE does not make public its reasons for prioritising HSTs. It could also be argued that in specifically reaffirming its rejection of the rule of rescue in its new statement of principles, while failing in the same document to explicitly acknowledge or explain the basis for its prioritisation of HSTs, NICE adopts a strategy that purposefully obscures a problematic aspect of its approach. That is, it could be suggested that in claiming to reject the rule of rescue, NICE implies that it is able to respond to the moral complexities of these 'rescue' scenarios with its basic approach intact, when, in fact, the HST programme provides it

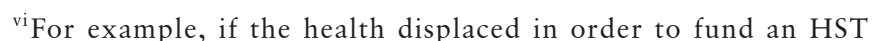
relates to services to relieve mild pain caused by ingrown toenails - a relatively small burden that might be considered normatively irrelevant in comparison with the burden suffered by the HST
} patient. with a means of 'muddling through" ${ }^{41-43}$ these challenging cases only by substantially departing from this approach.

While this pragmatic strategy is understandable given the difficult job that NICE is tasked with, the resultant loss of transparency undermines its claim to act as a fair decision-maker, putting the legitimacy of its decisions at risk. It also relieves NICE of the immediate need to resolve apparent inconsistencies in its approach and to publicly account for the normative basis of some of its most contentious decisions. If NICE stands by these decisions, it must be willing to explain the true basis on which they have been made. In doing so, it is likely to find that reference to the rule of rescue, already unhelpful, becomes unnecessary.

\section{Twitter Victoria Charlton @VicCharlton}

Acknowledgements The author would like to thank Dr Joe Millum, Dr Polly Mitchell and Professor Albert Weale for providing helpful and insightful feedback on an early version of this article. The author is also extremely grateful for the constructive comments of three anonymous reviewers, which allowed her to see things through a slightly different lens. Finally, the author would like to thank Dr Courtney Davis and Dr Annette Rid for their continued support to the wider project of which this forms part.

Contributors VC solely conceived, researched, wrote and revised this article.

Funding This research was funded by a Wellcome Trust Society and Ethics Doctoral Studentship (Grant number 203351/Z/16/Z).

Competing interests None declared.

Patient consent for publication Not required.

Provenance and peer review Not commissioned; externally peer reviewed. Data availability statement All data relevant to the study are included in the article.

Open access This is an open access article distributed in accordance with the Creative Commons Attribution 4.0 Unported (CC BY 4.0) license, which permits others to copy, redistribute, remix, transform and build upon this work for any purpose, provided the original work is properly cited, a link to the licence is given, and indication of whether changes were made. See: https://creativecommons.org/ licenses/by/4.0/.

\section{ORCID iD}

Victoria Charlton http://orcid.org/0000-0002-7407-2627

\section{REFERENCES}

1 NICE. Guide to the methods of technology appraisal, 2013. Available: https://www. nice.org.uk/process/pmg9/chapter/the-appraisal-of-the-evidence-and-structureddecision-making [Accessed Jul 2020].

2 NICE. The principles that guide the development of NICE guidance and standards, 2020. Available: https://www.nice.org.uk/about/who-we-are/our-principles [Accessed Jul 2020].

3 NICE. Interim process and methods of the highly specialised technologies programme: updated to reflect 2017 changes, 2017. Available: https://www.nice.org.uk/Media/ Default/About/what-we-do/NICE-guidance/NICE-highly-specialised-technologiesguidance/HST-interim-methods-process-guide-may-17.pdf [Accessed Jul 2020].

4 Jonsen AR. 3. Bentham in a box: technology assessment and health care allocation. Law, Medicine and Health Care 1986;14(3-4):172-4.

5 Hadorn D. The Oregon priority-setting exercise: cost-effectiveness and the rule of rescue, revisited. Med Decis Making 1996;16(2):117-9.

6 Hadorn DC. Setting health care priorities in Oregon. cost-effectiveness meets the rule of rescue. JAMA 1991;265(17):2218-25.

7 Lamb EJ. Rationing of medical care: rules of rescue, cost-effectiveness, and the Oregon plan. Am J Obstet Gynecol 2004;190(6):1636-41.

8 Osborne M, Evans TW. Allocation of resources in intensive care: a transatlantic perspective Lancet 1994:343(8900):778-80.

9 Largent EA, Pearson SD. Which orphans will find a home? the rule of rescue in resource allocation for rare diseases. Hastings Cent Rep 2012;42(1):27-34.

10 Jecker NS. The problem with rescue medicine. J Med Philos 2013:38(1):64-81.

11 Rulli T, Millum J. Rescuing the duty to rescue. J Med Ethics 2016;42(4):260-4.

12 McKie J, Richardson J. The rule of rescue. Soc Sci Med 2003;56(12):2407-19.

13 Sheehan M. Resources and the rule of rescue. J App/ Philos 2007;24(4):352-66.

14 Hope T. Rationing and life-saving treatments: should identifiable patients have higher priority? J Med Ethics 2001:27(3):179-85.

15 Cookson R, McCabe C, Tsuchiya A. Public healthcare resource allocation and the rule of rescue. J Med Ethics 2008;34(7):540-4 
16 Hughes J, Walker T. The rule of rescue in clinical practice. Clin Ethics 2009;4(1):50-4.

17 Brock DW. Ethical and value issues in insurance coverage for cancer treatment. Oncologist 2010;15 Suppl 1:36-42.

18 Cookson R. Can the NICE "end-of-life premium" be given a coherent ethical justification? J Health Polit Policy Law 2013:38(6):1129-48.

19 Parfit D. Equality or priority. The Lindley Lecture: University of Kansas, 1991.

20 Nicod E, Kanavos P. Scientific and social value judgments for orphan drugs in health technology assessment. Int J Technol Assess Health Care 2016;32(4):218-32.

21 Franken M, Stolk E, Scharringhausen T, et al. A comparative study of the role of disease severity in drug reimbursement decision making in four European countries. Health Policy 2015;119(2):195-202.

22 Stafinski T, Menon D, Davis C, et al. Role of centralized review processes for making reimbursement decisions on new health technologies in Europe. Clinicoecon Outcomes Res 2011;3:117-86.

23 Daniels N. Reasonable disagreement about identified vs. statistical. Hastings Cent Rep 2012:42(1):35-45

24 Jenni K, Loewenstein G. Explaining the identifiable victim effect. J Risk Uncertain 1997:14(3):235-57

25 HM Government. Health and social care act 2012. Part 8, section 223, 2012

26 Simoens S. Health technologies for rare diseases: does conventional HTa still apply? Expert Rev Pharmacoecon Outcomes Res 2014:14(3):315-7.

27 NICE. Interim process and methods of the highly specialised technologies programme, 2013

28 NICE. Social value judgements: principles for the development of NICE guidance. 2nd Edition, 2008

29 Paterson KR. Value and cancer medicines-A personal view. J Cancer Policy 2017:11:26-31.

30 Small DA, Loewenstein G. Helping a victim or helping the victim: altruism and identifiability. J Risk Uncertain 2003:26(1):5-16.

31 Claxton K, Martin S, Soares M, et al. Methods for the estimation of the National Institute for health and care excellence cost-effectiveness threshold. Health Technol Assess 2015;19(14):1-504.

32 Lomas J, Martin S, Claxton K. Estimating the marginal productivity of the English National health service from 2003 to 2012. Value Health 2019:22(9):995-1002.

33 Wood EM, Hughes DA. The new and Non-Transparent cancer drugs fund. Pharmacoeconomics 2020;38(1):1-4.

34 Johnson R, Cureton A. "Kant's Moral Philosophy". The Stanford Encyclopedia of Philosophy (Spring 2019 Edition), Edward N. Zalta (ed.). Available: https://plato. stanford.edu/archives/spr2019/entries/kant-moral/ [Accessed Dec 2020].

35 NICE. PMG19 Addendum A - Final amendments to the NICE technology appraisal processes and methods guides to support the proposed new Cancer Drugs Fund arrangements, 2016

36 Medicines and Healthcare products Regulatory Agency. Guidance: how the MHRA will manage orphan medicinal products from 1 January 2021 in Great Britain (GB) 2020. Available: https://www.gov.uk/guidance/how-the-mhra-will-manage-orphanmedicinal-products-from-1-january-2021-in-great-britain-gb\#market-exclusivityperiod [Accessed Dec 2020].

37 Arneson R. "Egalitarianism". The Stanford Encyclopedia of Philosophy (Summer 2013 Edition), Edward N. Zalta (ed.). Available: https://plato.stanford.edu/archives/ sum2013/entries/egalitarianism [Accessed Dec 2020].

38 Lippert-Rasmussen K. "Justice and Bad Luck". The Stanford Encyclopedia of Philosophy (Summer 2018 Edition), Edward N. Zalta (ed.). Available: https://plato. stanford.edu/archives/sum2018/entries/justice-bad-luck [Accessed Dec 2020].

39 Voorhoeve A. Balancing small against large burdens. Behav Public Policy 2018:2(1):125-42

40 Daniels N, Sabin J. Limits to health care: fair procedures, Democratic deliberation, and the legitimacy problem for insurers. Philos Public Aff 1997;26(4):303-50.

41 Lindblom CE. The Science of "Muddling Through". Public Adm Rev 1959;19(2):79-88.

42 Mechanic D. Muddling through elegantly: finding the proper balance in rationing. Health Aff 1997; 16(5):83-92.

43 Hunter DJ. Rationing: the case for "muddling through elegantly". BMJ 1995:311(7008):811.

44 Towse A, Garau M. Appraising Ultra-Orphan drugs: is Cost-Per-QALY appropriate? A review of the evidence. office of health economics, 2018. Available: https://www.ohe. org/publications/appraising-ultra-orphan-drugs-cost-qaly-appropriate-review-evidence [Accessed Jul 2020].

45 NICE. Final evaluation determination: eculizumab for treating atypical haemolytic uraemic syndrome. Hst1, 2015. Available: https://www.nice.org.uk/guidance/hst1 [Accessed Jul 2020].

46 NICE. Evaluation Consultation Document 1: Atypical haemolytic uraemic syndrome (aHUS) - eculizumab. HST1, 2014. Available: https://www.nice.org.uk/guidance/ hst1/documents/atypical-haemolytic-uraemic-syndrome-ahus-eculizumab-evalutionconsultation-document [Accessed Nov 2020].

47 NICE. Evaluation Consultation Document 2: Atypical haemolytic uraemic syndrome (aHUS) - eculizumab. HST1, 2014. Available: https://www.nice.org.uk/guidance/ hst1/documents/atypical-haemolytic-uraemic-syndrome-ahus-eculizumab-evalutionconsultation-document-2 [Accessed Nov 2020].

48 NICE. Final evaluation determination: Elosulfase alfa for treating mucopolysaccharidosis type IVA. HST2, 2015. Available: https://www.nice.org.uk/ guidance/hst2 [Accessed Jul 2020].

49 NICE. Evaluation consultation document 1: Elosulfase alfa for treating mucopolysaccharidosis type IVA. HST2, 2015. Available: https://www.nice.org
uk/guidance/HST2/documents/mucopolysaccharidosis-type-iva-elosulfase-alfaevaluation-consultation3 [Accessed Nov 2020].

50 NICE. Evaluation consultation document 2: Elosulfase alfa for treating mucopolysaccharidosis type IVA. HST2, 2015. Available: https://www.nice.org.uk/ guidance/hst2/documents/mucopolysaccharidosis-type-iva-elosulfase-alfa-evaluationconsultation-23 [Accessed Nov 2020]

51 NICE. Final evaluation determination: Ataluren for treating Duchenne muscular dystrophy with a nonsense mutation in the dystrophin gene. Hst3, 2016. Available: https://www.nice.org.uk/guidance/hst3 [Accessed Jul 2020].

52 NICE. Evaluation consultation document: Ataluren for treating Duchenne muscular dystrophy with a nonsense mutation in the dystrophin gene. Hst3, 2015. Available: https://www.nice.org.uk/guidance/hst3/documents/evaluation-consultation-document [Accessed Nov 2020].

53 NICE. Final evaluation determination: Migalastat for treating Fabry disease. HST4 2017. Available: https://www.nice.org.uk/guidance/hst4 [Accessed Jul 2020].

54 NICE. Evaluation consultation document: Migalastat for treating Fabry disease. HST4, 2016. Available: https://www.nice.org.uk/guidance/hst4/documents/evaluationconsultation-document [Accessed Nov 2020].

55 NICE. Final evaluation determination: Eliglustat for treating type 1 Gaucher disease. HST5, 2017. Available: https://www.nice.org.uk/guidance/hst5 [Accessed Jul 2020].

56 NICE. Evaluation consultation document: Eliglustat for treating type 1 Gaucher disease. HST5, 2017. Available: https://www.nice.org.uk/guidance/hst5/documents/ evaluation-consultation-document [Accessed Nov 2020].

57 NICE. Final evaluation determination: Asfotase alfa for treating paediatric-onset hypophosphatasia. HST6, 2017. Available: https://www.nice.org.uk/guidance/hst6 [Accessed Jul 2020].

58 NICE. Evaluation consultation document 1: Asfotase alfa for treating paediatriconset hypophosphatasia. HST6, 2015. Available: https://www.nice.org.uk/ guidance/hst6/documents/evaluation-consultation-document [Accessed Nov 2020].

59 NICE. Evaluation consultation document 2: Asfotase alfa for treating paediatric-onset hypophosphatasia. HST6, 2016. Available: https://www.nice.org.uk/guidance/hst6/ documents/evaluation-consultation-document-2 [Accessed Nov 2020].

60 NICE. Final evaluation determination: Strimvelis for treating adenosine deaminase deficiency-severe combined immunodeficiency. HST7, 2018. Available: https://www. nice.org.uk/guidance/hst7 [Accessed Jul 2020]

61 NICE. Evaluation consultation document: Strimvelis for treating adenosine deaminase deficiency-severe combined immunodeficiency. HST7, 2017. Available: https://www. nice.org.uk/guidance/hst7/documents/evaluation-consultation-document [Accessed Nov 2020]

62 NICE. Final evaluation determination: Burosumab for treating X-linked hypophosphataemia in children and young people. HST8, 2018. Available: https:// www.nice.org.uk/guidance/hst8 [Accessed Jul 2020].

63 NICE. Evaluation consultation document: Burosumab for treating X-linked hypophosphataemia in children and young people. HST8, 2018. Available: https:/ www.nice.org.uk/guidance/hst8/documents/evaluation-consultation-document-2 [Accessed Nov 2020].

64 NICE. Final evaluation determination: Inotersen for treating hereditary transthyretin amyloidosis. HST9, 2019. Available: https://www.nice.org.uk/guidance/hst9 [Accessed Jul 2020].

65 NICE. Evaluation consultation document: Inotersen for treating hereditary transthyretinrelated amyloidosis. HST9, 2018. Available: https://www.nice.org.uk/ guidance/hst9/documents/evaluation-consultation-document [Accessed Nov 2020].

66 NICE. Final evaluation determination: Patisiran for treating hereditary transthyretin amyloidosis. HST10, 2019. Available: https://www.nice.org.uk/guidance/hst10 [Accessed Jul 2020].

67 NICE. Evaluation consultation document: Patisiran for treating hereditary transthyretinrelated amyloidosis. HST10, 2018. Available: https:/www.nice.org.uk/ guidance/hst10/documents/evaluation-consultation-document [Accessed Nov 2020]

68 NICE. Final evaluation determination: Voretigene neparvovec for treating inherited retinal dystrophies caused by RPE65 gene mutations. HST11, 2019. Available: https:// www.nice.org.uk/guidance/hst11 [Accessed Jul 2020].

69 NICE. Final evaluation determination 2: Cerliponase alfa for treating neuronal ceroid lipofuscinosis type 2. HST12, 2019. Available: https://www.nice.org.uk/guidance/ hst12 [Accessed Jul 2020]

70 NICE. Evaluation consultation document: Cerliponase alfa for treating neurona ceroid lipofuscinosis type 2. HST12, 2018. Available: https://www.nice.org.uk/ guidance/hst12/documents/evaluation-consultation-document [Accessed Nov 2020].

71 NICE. Final evaluation determination 1: Cerliponase alfa for treating neuronal ceroid lipofuscinosis type 2. HST12, 2019. Available: https://www.nice.org.uk/guidance/ hst12/documents/final-evaluation-determination-document [Accessed Nov 2020]

72 NICE. Final evaluation determination: Volanesorsen for treating familial chylomicronaemia syndrome. hst 13, 2020. Available: https://www.nice.org.uk/ guidance/hst13 [Accessed Nov 2020].

73 NICE. Evaluation consultation document: Volanesorsen for treating familial chylomicronaemia syndrome. hst 13, 2019. Available: https://www.nice.org.uk/ guidance/hst13/documents/evaluation-consultation-document [Accessed Nov 2020].

74 Donnelly L. NHS agrees to fund drug for children with incurable Batten disease after High Court threat. The Telegraph, 2019. Available: https://www.telegraph.co.uk/news/ 2019/09/11/nhs-agrees-fund-drug-children-incurable-disease-high-court-threat/ [Accessed Jul 2020]. 